\title{
Liquid crystalline properties of unsymmetrically substituted phthalocyanines: structural features leading to nematic mesophase materials
}

\author{
Andrew D. Garland, Geoffrey C. Bryant, Isabelle Chambrier, Andrew N. Cammidge* \\ and Michael J. Cook ${ }^{*}$
}

Dedicated to Professor Nagao Kobayashi on the occasion of his 65th birthday

School of Chemistry, University of East Anglia, Norwich Research Park, Norwich, NR4 7TJ, UK.

Received date (to be automatically inserted after your manuscript is submitted)

Accepted date (to be automatically inserted after your manuscript is accepted)

\begin{abstract}
A novel homologous series of four 1,4,8,11,15,18-hexakis(pentyl)-22-methyl-25hydroxyalkylphthalocyanine derivatives with the hydroxyalkyl chain varying from hydroxynonyl through to hydroxydodecyl has been synthesized to investigate the role of the hydroxyalkyl chain in promoting thermotropic liquid crystalline behavior. Polarizing optical miscoscopy reveals that the compound with the shortest hydroxyalkyl chain (hydroxynonyl) exhibits a mesophase with a texture characteristic of a columnar mesophase, common among liquid crystalline phthalocyanine derivatives. However, as the chain is lengthened along the series, there appears a second type of mesophase that shows a schlieren texture. Such a texture is characteristic of a nematic phase and rare among liquid crystalline phthalocyanine derivatives. A fifth compound, the novel 1,4,8,11,15,18-hexakis(pentyl)-22-methyl-25dodecylphthalocyanine, exhibits only columnar mesophase behavior suggesting that the hydroxyl group at the end of the longer chains of the former compounds is important in developing the nematic phase.
\end{abstract}

KEYWORDS: liquid crystalline phthalocyanines, columnar mesophase, nematic discotic mesophase

*Correspondence to: Andrew N Cammidge, email a.cammidge@uea.ac.uk or Michael J Cook, email m.cook@uea.ac.uk 


\section{INTRODUCTION}

The first examples of liquid crystalline phthalocyanines were reported by Simon and coworkers in 1982 [1]. Their discovery added examples of the then recently identified class of 'discotic' liquid crystals [2], typically near planar molecules bearing a number of paraffinic chains that exhibit columnar ( $\mathrm{Col}$ ) mesophases. The compounds developed by Simon's group carried eight alkoxymethyl chains at the peripheral $(2,3,9,10,16,17,23,24-)$ sites of the phthalocyanine structure [1,3,4,5]. The UEA group then reported that compounds bearing eight medium length alkyl [6-9] or alkoxymethyl groups $[10,11]$ at the non-peripheral $(1,4,8,11,15,18,22,25-)$ sites of the macrocycle, as metal-free or $\mathrm{M}^{\mathrm{II}}$ metallated derivatives, also exhibited columnar mesophase behavior. The same group further established that columnar liquid crystal phases were exhibited by non-uniformly substituted phthalocyanines such as those depicted in Fig 1 [1216]. Nowadays there is a broad range of liquid crystalline phthalocyanine derivatives available [17] and, for some examples, there is particular interest in their electrical conductivities. Time of Flight (TOF) mobility studies have established that a number of such compounds in mesophase states exhibit ambipolar properties, showing both high hole and electron transport [18-21].

Fig 1 here

In general, columnar mesophase formation in discotic systems is now well understood and qualitative design parameters are known in order to promote such mesophase formation from a variety of aromatic cores [22, 23]. The most intensively investigated cores are triphenylene, hexabenzocoronene and phthalocyanine, where introduction of flexible (saturated) side-chains leads to formation of columnar mesophases. Columnar mesophase formation can be rationalized through consideration of molecular interaction and packing constraints, and molecules in a columnar phase can be broken down into their two components - the cores stack together and are separated by the hydrocarbon chain regions. Much rarer are discotic nematic mesophases [24], where the molecules possess orientational order but the columnar arrangement (positional order) is lost (Fig. 2). Significant progress has been made to induce nematic mesophase formation with some cores and a set of design parameters is emerging. In all cases, nematic mesophase formation requires a destabilization of a columnar arrangement and it is typically achieved by introducing packing constraints (e.g. the triphenylene hexabenzoate esters [25]) or breaking the symmetry in the discotic molecule. More recently a complementary approach has emerged whereby columnar mesophase behavior is suppressed through rigid linking $[26,27]$ or twinning $[28,29]$ of discotic components, leading to nematic mesophase formation in triphenylenebased systems. Within the phthalocyanine series no conclusive examples of thermotropic nematic mesophase formation have been reported to date [30].

\section{Fig 2 here}

From earlier research we know that introduction of eight appropriate alkyl chains on the four benzenoid units of 1,4,8,11,15,18,22,25-octaalkylphthalocyanine leads to formation of stable columnar mesophases. Hexyl chains are the shortest substituents that can be employed for the metal-free derivative because we know that eight pentyl groups are insufficient to promote mesophase behavior [6,7], placing this symmetrical derivative at the limit of mesophase formation. This has led to its selection as the parent structure for modification in order to investigate the effect of both symmetry breaking and introduction of a hydrophilic terminal group. We therefore demonstrate here that replacement of two pentyl groups on one of the benzenoid units of the parent symmetrical structure by a methyl substituent and a 
hydroxyalkyl chain, type $\mathbf{C}$ compounds in Fig. 1, can induce not merely liquid crystal behavior but different types of mesophases.

\section{RESULTS AND DISCUSSION}

\section{Preparation of compounds}

\section{Scheme 1 here}

The series of novel compounds 1-4 was prepared according to the route depicted in Scheme 1. The synthetic scheme has been exploited earlier by us to provide examples of homologues of type $\mathbf{C}$ where the six alkyl chains on three of the benzenoid rings are hexyl, octyl or undecyl groups and with various length hydroxyalkyl chain on the fourth benzenoid ring [13-16]. In the present work, the mixed cyclisation of two phthalonitrile derivatives, a 3-methyl-6-hydroxyalkyl phthalonitrile and 3,6-dipentylphthalonitrile, step iii in Scheme 1, produces the desired phthalocyanine compound along with 1,4,8,11,15,18,22,25-octakis(pentyl)phthalocyanine as the main side-product together with limited amounts of other cross condensation products. Yields and characterization data for novel compounds are collected in the Experimental section.

In addition, to investigate the role of the $\mathrm{OH}$ group on mesophase behavior, we converted a sample of $\mathbf{4}$ into the novel unsymmetrically substituted octakis(alkyl) derivative $\mathbf{5}$ via the chemistry shown in Scheme 2.

\section{Scheme 2 here}

\section{Mesophase behavior}

Mesophase behavior was investigated by polarizing optical microscopy (POM) and DSC and is summarized in Table 1. Phthalocyanine 1, bearing the shortest hydroxyalkyl substituent, displays a relatively narrow columnar hexagonal mesophase. However, phthalocyanines 2-4, bearing hydroxydecyl, hydroxyundecyl and hydroxydodecyl chains respectively, show a different mesophase, characterized as discotic nematic based on the distinctive texture observed by POM (Fig. 3), and the relative low viscosity of the mesophase. The presence of the terminal hydroxyl group is crucial for nematic mesophase formation - phthalocyanine $\mathbf{5}$, bearing a simple dodecyl group, forms exclusively columnar hexagonal and columnar rectangular phases, behavior that is typical of non-peripherally substituted hexaalkylphthalocyanines [7].

It is possible to speculate on the origin of this dramatic effect, where nematic mesophase formation is clearly driven by the hydrophilic end group. In phthalocyanine 1 the preferred core-core separation in a columnar arrangement $(2 \times$ pentyl chains) matches perfectly with placement of the hydroxyl group close to the aza-bridge of a Pc in a neighboring column. Hydrogen-bonding is possible to further stabilize the arrangement. Lengthening the link to the hydrophilic hydroxyl group disturbs this arrangement - forcing a buckling of the chain or forcing the hydroxyl group into the hydrophobic interstitial region or the columnar stack. The columnar arrangement is no longer favored and the nematic mesophase is formed.

\section{Table here}


Fig 3 here

\section{EXPERIMENTAL}

\section{Spectroscopic and physicochemical methods}

${ }^{1} \mathrm{H}$ NMR spectra were recorded on a Jeol $250 \mathrm{MHz}$ spectrometer. Signals are quoted in ppm as $\delta$ downfield from tetramethylsilane $(\delta=0.00)$. Ultra-violet spectra of the phthalocyanine derivatives were recorded on a Hitachi U-3000 spectrophotometer using cyclohexane as solvent. MALDI-ToF mass analysis was carried out using a Shimadzu MALDIToF spectrometer with a TA1586Ade plate and DCTB (trans-2-[3-(4-tert-butylphenyl)-2-methyl-2-propenylidene] malononitrile) as matrix. Elemental analyses were undertaken by Mr A Saunders at UEA and results provided were within acceptable error margins. Column chromatography was performed at room temperature using Aldrich ${ }^{\circledR}$ neutral silica and reagent grade solvents as eluents. Liquid crystalline behavior was investigated using an Olympus BH2 polarizing microscope with a Linkham THM600 hot stage, and with a TA Instruments DSC 10 instrument coupled to a TA200 workstation.

\section{Preparation of intermediates (see Scheme 1)}

Preparation of 2-methyl-5-[(2-tetrahydropyranyloxy)alkyl]furans. The synthesis of 2-methyl-5-[9-(2tetrahydropyranyloxy)nonyl]furan and 2-methyl-5-[11-(2-tetrahydropyranyloxy)undecyl]furan have been described elsewhere [16]. Application of the same protocol provided the novel homologues used in this work viz 2-methyl-5-[10(2-tetrahydropyranyloxy)decyl]furan obtained as an oil, yield 99\%, and 2-methyl-5-[12-(2tetrahydropyranyloxy)dodecyl]furan as an oil, yield $98 \%$.

Preparation of 3-methyl-6-hydroxyalkylphthalonitriles. The synthesis of 3-methyl-6-(9hydroxynonyl)phthalonitrile and 3-methyl-6-(11-hydroxyundecyl)phthalonitrile have been reported elsewhere [16]. The same protocol provided the novel homologue 3-methyl-6-(9-hydroxydecyl)phthalonitrile, yield $23 \%$, mp 66-67 ${ }^{\circ} \mathrm{C}$. Found: C, 76.23; $\mathrm{H} \mathrm{8.81;} \mathrm{N} \mathrm{9.00 \% .} \mathrm{C}_{19} \mathrm{H}_{26} \mathrm{~N}_{2} \mathrm{O}$ requires: C, 76.47; $\mathrm{H} 8.78 ; \mathrm{N} 9.39 \% .{ }^{1} \mathrm{H}$ NMR $\left(\mathrm{CDCl}_{3}\right): \delta \mathrm{ppm} 1.20-$ $2.00(17 \mathrm{H}, \mathrm{m}), 2.56(3 \mathrm{H}, \mathrm{s}) 2.84(2 \mathrm{H}, \mathrm{t})$. The novel 3-methyl-6-(9-hydroxydodecyl)phthalonitrile was obtained similarly, yield 28\%, mp 81-82. Found: C, 76.99; H 9.37; N 8.28\%. $\mathrm{C}_{21} \mathrm{H}_{30} \mathrm{~N}_{2} \mathrm{O}$ requires: C, 77.26; $\mathrm{H} 9.26 ; \mathrm{N} 8.58 \%$. ${ }^{1} \mathrm{H}$ NMR $\left(\mathrm{CDCl}_{3}\right): \delta \mathrm{ppm} 1.20-2.00(17 \mathrm{H}, \mathrm{m}), 2.56(3 \mathrm{H}, \mathrm{s}) 2.84(2 \mathrm{H}, \mathrm{t})$.

\section{Preparation of phthalocyanine derivatives}

Preparation of 1,4,8,11,15,18-hexakis(pentyl)-22-methyl-25-(hydroxyalkyl)phthalocyanines 1 -4. In a typical procedure, following that described for the synthesis of the homologous 1,4,8,11,15,18-hexakis(hexyl)-22-methyl-25(hydroxyalkyl)phthalocyanines [16], the individual 3-methyl-6-hydroxyalkylphthalonitriles above (1 mmol) were separately reacted with 3,6-bis(pentyl)phthalonitrile [8], (2.6 g, $9 \mathrm{mmol})$ in a solution of 1-pentanol (25 ml) heated under reflux to which was slowly added lithium metal $(0.30 \mathrm{~g}, 2.7 \mathrm{~g} 9 \mathrm{mmol})$. The reaction mixture was heated under reflux for $18 \mathrm{~h}$ and protected from atmospheric moisture by a $\mathrm{CaCl}_{2}$ drying tube. The reaction was cooled to $\mathrm{rt}$ and glacial acetic acid added. The solution was stirred for $30 \mathrm{~min}$. The solvents were removed by distillation under reduced pressure and the product chromatographed twice over silica. The first partial separation was achieved by elution first 
with petrol and then THF. The green components were then collected and chromatographed again (eluent cyclohexane, followed by cyclohexane/THF $2: 1$ by volume) which achieved separation of the 1,4,8,11,15,18-hexakis(pentyl)-22methyl-25-(hydroxyalkyl)phthalocyanine from 1,4,8,11,15,18,22,25-octakis(pentyl)phthalocyanine and other minor products. The protocol provided the following derivatives:

1,4,8,11,15,18-Hexakis(pentyl)-22-methyl-25-(9-hydroxynonyl)phthalocyanine 1. Yield 10\%. Found: C, 79.42; H, 8.99; N,10.11\%. $\mathrm{C}_{72} \mathrm{H}_{98} \mathrm{~N}_{8} \mathrm{O}$ requires: $\mathrm{C}, 79.22 ; \mathrm{H}, 9.05 ; \mathrm{N}, 10.26 \% .{ }^{1} \mathrm{H}$ NMR $\left(\mathrm{C}_{6} \mathrm{D}_{6}\right): \delta \mathrm{ppm}-0.63(2 \mathrm{H}, \mathrm{s}), 0.87-0.99$ $(18 \mathrm{H}, \mathrm{m}), 1.13-1.79(36 \mathrm{H}, \mathrm{m}), 2.11-2.35(14 \mathrm{H}, \mathrm{m}), 3.22-3.26(2 \mathrm{H}, \mathrm{m}), 3.57(1 \mathrm{H}, \mathrm{s}), 3.65(3 \mathrm{H}, \mathrm{s}), 4.33-4.36(2 \mathrm{H}, \mathrm{m})$, 4.50-4.71 (12H, m), $7.55(1 \mathrm{H}, \mathrm{d}), 7.64-7.72(3 \mathrm{H}, \mathrm{m}), 7.84$ (4H, s). UV-vis (cyclohexane): $\lambda, \mathrm{nm}(\log \varepsilon) 728(5.05), 692$ (4.97), 664 (4.56), 628 (4.36), 357 (4.66), 310 (4.57).

1,4,8,11,15,18-Hexakis(pentyl)-22-methyl-25-(10-hydroxydecyl)phthalocyanine 2. Yield 4\%. Found: C, 79.18; H, 9.29; N,10.11\%. $\mathrm{C}_{73} \mathrm{H}_{100} \mathrm{~N}_{8} \mathrm{O}$ requires: $\mathrm{C}, 79.30 ; \mathrm{H}, 9.12 ; \mathrm{N}, 10.13 \%$. ${ }^{1} \mathrm{H}$ NMR $\left(\mathrm{C}_{6} \mathrm{D}_{6}\right): \delta \mathrm{ppm}-0.62(2 \mathrm{H}, \mathrm{s}), 0.86-0.97$ $(18 \mathrm{H}, \mathrm{m}), 1.09-1.78(38 \mathrm{H}, \mathrm{m}), 2.08-2.33(14 \mathrm{H}, \mathrm{m}), 3.25(2 \mathrm{H}, \mathrm{t}), 3.63(1 \mathrm{H}, \mathrm{s}), 3.65(3 \mathrm{H}, \mathrm{s}), 4.31(2 \mathrm{H}, \mathrm{t}), 4.51-4.71(12 \mathrm{H}$, $\mathrm{m}), 7.53(1 \mathrm{H}, \mathrm{d}), 7.64-7.71(3 \mathrm{H}, \mathrm{m}), 7.83(4 \mathrm{H}, \mathrm{s})$. (The signal for the $\mathrm{OH}$ proton was not observed). UV-vis (cyclohexane): $\lambda, \mathrm{nm}$ (log $\varepsilon) 728$ (5.09), 691 (5.01), 663 (4.59), 628 (4.40), 357 (4.71), 310 (4.61).

1,4,8,11,15,18-Hexakis(pentyl)-22-methyl-25-(11-hydroxyundecyl)phthalocyanine 3. Yield 26\%. Found: C, 79.24; $\mathrm{H}, 9.29 ; \mathrm{N}, 9.77 \% . \mathrm{C}_{74} \mathrm{H}_{102} \mathrm{~N}_{8} \mathrm{O}$ requires: $\mathrm{C}, 79.38 ; \mathrm{H}, 9.18 ; \mathrm{N}, 10.01 \%$. ${ }^{1} \mathrm{H}$ NMR $\left(\mathrm{C}_{6} \mathrm{D}_{6}\right): \delta \mathrm{ppm}-0.62(2 \mathrm{H}, \mathrm{s}), 0.86-$ $0.97(18 \mathrm{H}, \mathrm{m}), 1.12-1.78(40 \mathrm{H}, \mathrm{m}), 2.11-2.31(14 \mathrm{H}, \mathrm{m}), 3.27(2 \mathrm{H}, \mathrm{t}), 3.64(3 \mathrm{H}, \mathrm{s}), 4.33(2 \mathrm{H}, \mathrm{t}), 4.50-4.71(12 \mathrm{H}, \mathrm{m})$, $7.53(1 \mathrm{H}, \mathrm{d}), 7.64-7.71(3 \mathrm{H}, \mathrm{m}), 7.84(4 \mathrm{H}, \mathrm{s})$. (The signal for the $\mathrm{OH}$ proton was not observed). UV-vis (cyclohexane): $\lambda, \mathrm{nm}(\log \varepsilon) 727$ (5.08), 691 (4.49), 664 (sh), 629 (4.40), 356 (4.70), 310 (4.59).

1,4,8,11,15,18-Hexakis(pentyl)-22-methyl-25-(12-hydroxydodecyl)phthalocyanine 4. Yield 22\%. Found: C, 79.49; $\mathrm{H}, 9.27 ; \mathrm{N}, 9.80 \%$. $\mathrm{C}_{75} \mathrm{H}_{104} \mathrm{~N}_{8} \mathrm{O}$ requires: $\mathrm{C}, 79.46 ; \mathrm{H}, 9.25 ; \mathrm{N}, 9.88 \%$. ${ }^{1} \mathrm{H}$ NMR $\left(\mathrm{C}_{6} \mathrm{D}_{6}\right): \delta \mathrm{ppm}-0.61(2 \mathrm{H}, \mathrm{s}), 0.81-$ $0.97(18 \mathrm{H}, \mathrm{m}), 1.14-1.77(42 \mathrm{H}, \mathrm{m}), 2.12-2.31(14 \mathrm{H}, \mathrm{m}), 3.28(2 \mathrm{H}, \mathrm{t}), 3.65(3 \mathrm{H}, \mathrm{s}), 4.33(2 \mathrm{H}, \mathrm{t}), 4.51-4.71(12 \mathrm{H}, \mathrm{m})$, $7.54(1 \mathrm{H}, \mathrm{d}), 7.65-7.72(3 \mathrm{H}, \mathrm{m}), 7.84(4 \mathrm{H}, \mathrm{s})$. (The signal for the $\mathrm{OH}$ proton was not observed). UV-vis (cyclohexane): $\lambda, \mathrm{nm}(\log \varepsilon) 727$ (5.10), 691 (5.02), 664 (4.60), 628 (4.41), 357 (4.72), 311 (4.62).

Preparation of 1,4,8,11,15,18-hexakis(pentyl)-22-methyl-25-dodecylphthalocyanine 5. Triethylamine $(0.5 \mathrm{ml})$ and methanesulfonyl chloride $(0.25 \mathrm{ml})$ were added sequentially to a solution of $1,4,8,11,15,18$-hexakis(pentyl)-22methyl-25-(12-hydroxydodecyl)phthalocyanine (4) (96 mg) in dry dichloromethane (10 ml). The solution was stirred for $1 \mathrm{~h}$. Water $(20 \mathrm{ml})$ was added and the mixture shakened and separated. The organic layer was dried and evaporated to dryness. The residue was chromatographed over silica, eluent cyclohexane/THF, and the mesylate derivative of 4 (78 $\mathrm{mg}, 79 \%$ ) collected and triturated using THF/methanol. A portion of the product (73 mg) was dissolved in dry THF (15 $\mathrm{ml}$ ) to which was added lithium triethylborohydride (Super-Hydride®) (1.0 M solution in THF, $1.0 \mathrm{ml}$ ). The reaction mixture was stirred at $\mathrm{rt}$ for $1 \mathrm{~h}$ and then quenched with water $(1 \mathrm{ml})$. Solvents were removed under reduced pressure and the residue chromatographed over silica (eluent cyclohexane/THF). The product was triturated with methanol to yield the title compound $(20 \mathrm{mg}, 30 \%)$ as a dark green wax. Found: $\mathrm{C}, 80.65 ; \mathrm{H}, 9.14 ; \mathrm{N}, 9.70 \%$. $\mathrm{C}_{75} \mathrm{H}_{104} \mathrm{~N}_{8}$ requires: $\mathrm{C}$, 80.60; H, 9.38; N, 10.03\%. ${ }^{1} \mathrm{H}$ NMR $\left(\mathrm{C}_{6} \mathrm{D}_{6}\right): \delta \mathrm{ppm}-0.60(2 \mathrm{H}, \mathrm{s}), 0.79-0.94(21 \mathrm{H}, \mathrm{m}), 1.15-1.75(42 \mathrm{H}, \mathrm{m}), 2.14-2.28$ $(14 \mathrm{H}, \mathrm{m}), 3.66(3 \mathrm{H}, \mathrm{s}), 4.30-4.40(2 \mathrm{H}, \mathrm{m}), 4.52-4.70(12 \mathrm{H}, \mathrm{m}), 7.50-7.55(1 \mathrm{H}, \mathrm{m}), 7.62-7.72(3 \mathrm{H}, \mathrm{m}), 7.81(4 \mathrm{H}, \mathrm{s}) . \mathrm{MS}$ (Maldi-tof) $m / z, 1118\left(\mathrm{M}^{+}\right)$. UV-vis (cyclohexane): $\lambda$, nm (log $\varepsilon$ ) 727 (5.14), 691 (5.06), 664 (4.63), 628 (4.45), 355 (4.75), 310 (4.65).

\section{CONCLUSION}


Rare nematic mesophase formation is induced in non-peripherally substituted phthalocyanines by introduction of a hydrophilic hydroxyl group at the terminus of a single side-chain of appropriate length. The nematic mesophase is formed exclusively when the linking chain is significantly longer than the natural separation between cores in the columnar arrangement of pentyl-substituted phthalocyanines and further demonstrates the subtle balance between molecular packing and interaction that drives self-assembly in discotic systems.

Acknowledgements We thank the EPSRC for financial support to IC (Research Grant), GCB and ADG (studentships).

\section{REFERENCES}

1. $\quad$ Piechocki C, Simon J, Skoulios A, Guillon D and Weber P. J. Am. Chem. Soc. 1982; 104: 5245 -5247.

2. Chandrasekhar S, Sadashiva BK and Suresh KA. Pramana 1977; 9: 471-480.

3. Guillon D, Skoulios A, Piechocki C. Simon J and Weber P. Mol. Cryst. Liq. Cryst. 1983; 100: 275-284.

4. Guillon D, Weber P, Skoulios A, Piechocki C and Simon J. Mol. Cryst. Liq. Cryst. 1985; 130: $223-229$.

5. Weber P, Guillon D and Skoulios A. J. Phys. Chem. 1987; 91: 2242-2243.

6. Cook MJ, Daniel MF, Harrison KJ, McKeown NB and Thomson AJ. J. Chem. Soc., Chem. Commun. 1987; 10861088.

7. Cherodian AS, Davies AN, Richardson RM, Cook MJ, McKeown NB, Thomson AJ, Feijoo J, Ungar G and Harrison KJ. Mol. Cryst. Liq. Cryst. 1991; 196: 103-114.

8. McKeown NB, Chambrier I and Cook MJ. J. Chem. Soc. Perkin Trans. 1 1990; 1169-1177.

9. Cook MJ, Cracknell SJ and Harrison KJ. J. Mater. Chem. 1991; 1: 703-704.

10. Cammidge AN, Cook MJ, Harrison KJ and McKeown NB. J. Chem. Soc. Perkin Trans. 1 1991; 3053-3058.

11. Cammidge AN, Cook MJ, Haslam SD, Richardson RM and Harrison KJ. Liquid Crystals 1993; 14: $1847-1862$

12. Chambrier I, Cook MJ, Cracknell SJ and McMurdo J. J. Mater. Chem. 1993; 3: 841-849.

13. Bryant GC, Cook MJ, Haslam SD, Richardson RM, Ryan TG and Thorne AJ. J. Mater. Chem. 1994; 4: $209-216$.

14. Bryant GC, Cook MJ, Ryan TG and Thorne AJ. Tetrahedron 1996; 52: 809-824.

15. Bryant GC, Cook MJ, Ryan TG and Thorne AJ. J. Chem. Soc., Chem. Commun. 1995; 467-468.

16. Chambrier I, Cook MJ, Mayes DA and MacDonald C. J. Porphyrins Phthalocyanines 2003; 7: 426-438.

17. Ohta K, Nguyen-Tran H-D, Tauchi L, Kanai Y, Megumi T and Takagi Y in Handbook of Porphyrin Science Vol. 12 (Eds Kadish K, Smith KM and Guilard R), World Scientific, Singapore, 2011, p1.

18. Iino H, Takayashiki Y, Hanna J-I and Bushby RJ. Jpn. J. Appl. Phys. 2005; 44: L1310

19. Iino H, Hanna J-I, Bushby RJ, Movaghar B, Whitaker BJ and Cook MJ. Appl. Phys. Lett. 2005; 87: 132102.

20. Miyake Y, Shiraiwa Y, Okada K, Monobe H, Hori T, Yamasaki N, Yoshida H, Cook MJ, Fugii A, Ozaki M and Shimizu Y. Appl. Phys. Express 2011; 4: 021604.

21. Shimizu Y, Miyake Y, Yoshida H, Monobe H, Cook MJ, Fugii A and Ozaki M. Mol. Cryst. Liq. Cryst. 2011; 549: 127-132.

22. Bushby RJ and Cammidge AN in Handbook of Liquid Crystals Vol. 2 (Eds Demus D, Goodby JW, Gray GW, Spiess H-W and Vill V), Wiley-VCH Verlag GmbH, Weinheim, 1997, p693.

23. Kumar S. Chem. Soc. Rev. 2006, 35, 83-109. 
24. Cammidge AN and Gopee $\mathrm{H}$ in Handbook of Liquid Crystals 2nd Ed., Vol. 3 (Eds Goodby JW, Collings PJ, Kato T, Tschierske C, Gleeson HF and Raynes P), Wiley-VCH Verlag GmbH, Weinheim, 2014, p293.

25. Hindmarsh P, Watson MJ, Hird M and Goodby JW. J. Mater. Chem. 1995, 5, 2111-2123.

26. Kumar S and Vashney SK. Org. Lett. 2002, 4, 157-159.

27. Cammidge AN and Gopee H. Liq. Cryst. 2009, 36, 809-816.

28. Zhang L, Gopee H, Hughes DL and Cammidge AN. Chem. Commun. 2010, 46, 4255-4257.

29. Zhang L, Hughes DL and Cammidge AN. J. Org. Chem. 2012, 77, 4288-4297.

30. Lelievre D, Petit MA and Simon J. Liq. Cryst. 1989, 4, 707-710. 
Captions

Fig. 1. Examples of series of non-uniformly substituted phthalocyanines as metal-free derivatives, $R=$ alkyl, that exhibit columnar liquid crystal behavior.

Fig. 2. Molecular arrangements is the (discotic) columnar mesophase and nematic mesophase.

Fig. 3. POM images of phthalocyanine $\mathbf{1}$ in its columnar hexagonal phase (left) and phthalocyanine $\mathbf{3}$ in the nematic phase (right). ( $\times 400$ magnification).

Scheme 1. i) 1-bromoalkyloxytetrahydropyran. ii) fumaronitrile, $\mathrm{LiN}\left(\mathrm{Me}_{3} \mathrm{Si}\right)_{2}$. iii) 3,6-dipentylphthalonitrile/ $\mathrm{LiOH} /$ pentanol.

Scheme 2. i) methylsulfonyl chloride/triethylamine. ii) Super-Hydride®.

Table 1. Thermal behavior of Phthalocyanines 1-5. Phases were identified by POM textures: $\mathrm{Cr}=\mathrm{Crystal}_{\mathrm{C}} \mathrm{Col}_{\mathrm{h}}=$ Columnar hexagonal, $\mathrm{Col}_{\mathrm{r}}=$ Columnar rectangular, $\mathrm{N}_{\mathrm{D}}=$ Discotic nematic, $\mathrm{I}=$ Isotropic fluid. (*Measured by microscopy. § Observed on cooling cycle only). 
Table 1. Thermal behavior of Phthalocyanines 1-5. Phases were identified by POM textures: $\mathrm{Cr}=\mathrm{Crystal}_{\mathrm{l}} \mathrm{Col}_{\mathrm{h}}=$ Columnar hexagonal, $\mathrm{Col}_{\mathrm{r}}=$ Columnar rectangular, $\mathrm{N}_{\mathrm{D}}=$ Discotic nematic, $\mathrm{I}=$ Isotropic fluid.

\begin{tabular}{|c|c|c|c|c|c|c|c|c|}
\hline $\begin{array}{l}\text { Compound } \\
\text { (long chain) }\end{array}$ & $\begin{array}{l}\text { Transition } \\
\text { data }\end{array}$ & $\mathrm{Cr}-\mathrm{Col}_{\mathrm{r}}$ & $\mathrm{Cr}^{-\mathrm{Col}_{\mathrm{h}}}$ & Cr-N $N_{D}$ & $\mathrm{Col}_{\mathrm{r}}-\mathrm{Col}_{\mathrm{h}}$ & $\begin{array}{l}\mathrm{Col}_{\mathrm{h}}-\mathrm{N}_{\mathrm{D}} \\
\S\end{array}$ & $\mathrm{N}_{\mathrm{D}}-\mathrm{I}$ & $\mathrm{Col}_{\mathrm{h}} \mathrm{-I}$ \\
\hline $\begin{array}{l}\mathbf{1} \\
\left(\mathrm{C}_{9} \mathrm{H}_{18} \mathrm{OH}\right)\end{array}$ & $\begin{array}{l}\mathrm{T}\left({ }^{\circ} \mathrm{C}\right) \\
\Delta \mathrm{H}\left(\mathrm{kcal} . \mathrm{mol}^{-1}\right) \\
\Delta \mathrm{S}\left(\text { cal. } \mathrm{mol}^{-1} \cdot \mathrm{K}^{-1}\right)\end{array}$ & & $\begin{array}{l}117.3 \\
2.8 \\
7.2\end{array}$ & & & & & $\begin{array}{l}132.2 \\
1.0 \\
2.6\end{array}$ \\
\hline $\begin{array}{l}2 \\
\left(\mathrm{C}_{10} \mathrm{H}_{20} \mathrm{OH}\right)\end{array}$ & $\begin{array}{l}\mathrm{T} \\
\Delta \mathrm{H} \\
\Delta \mathrm{S}\end{array}$ & & $\begin{array}{l}51.0^{*} \\
- \\
-\end{array}$ & & & $\begin{array}{l}(97.0) \\
(1.3) \\
(3.5)\end{array}$ & & $\begin{array}{l}109.0 \\
2.7 \\
2.6\end{array}$ \\
\hline $\begin{array}{l}\mathbf{3} \\
\left(\mathrm{C}_{11} \mathrm{H}_{22} \mathrm{OH}\right)\end{array}$ & $\begin{array}{l}\mathrm{T} \\
\Delta \mathrm{H} \\
\Delta \mathrm{S}\end{array}$ & & & $\begin{array}{l}66.4 \\
0.7 \\
2.1\end{array}$ & & & $\begin{array}{l}98.4 \\
0.6 \\
1.6\end{array}$ & \\
\hline $\begin{array}{l}\mathbf{4} \\
\left(\mathrm{C}_{12} \mathrm{H}_{24} \mathrm{OH}\right)\end{array}$ & $\begin{array}{l}\mathrm{T} \\
\Delta \mathrm{H} \\
\Delta \mathrm{S}\end{array}$ & & & $\begin{array}{l}88.1 \\
0.8 \\
2.1\end{array}$ & & & $\begin{array}{l}98.0 \\
0.2 \\
0.4\end{array}$ & \\
\hline $\begin{array}{l}\mathbf{5} \\
\left(\mathrm{C}_{12} \mathrm{H}_{25}\right)\end{array}$ & $\begin{array}{l}\mathrm{T} \\
\Delta \mathrm{H} \\
\Delta \mathrm{S}\end{array}$ & $\begin{array}{l}46.4 \\
2.0 \\
6.1\end{array}$ & & & $\begin{array}{l}99.6^{*} \\
- \\
-\end{array}$ & & & $\begin{array}{l}123.2 \\
0.8 \\
2.0\end{array}$ \\
\hline
\end{tabular}

*Measured by microscopy. § Observed on cooling cycle only. 
Fig 1

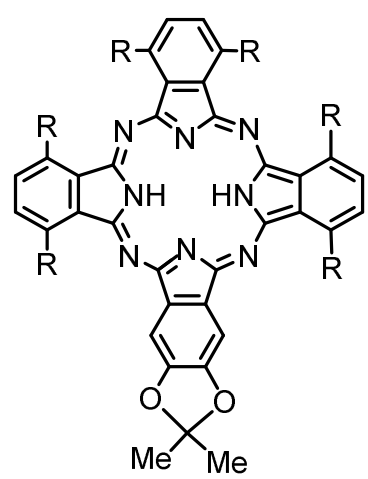

A

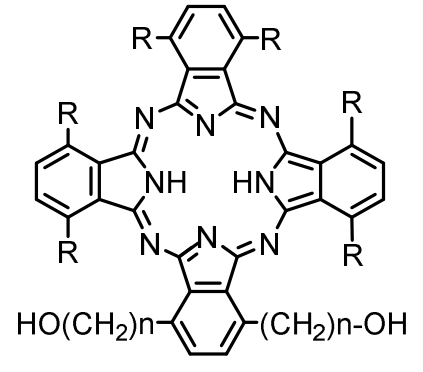

B

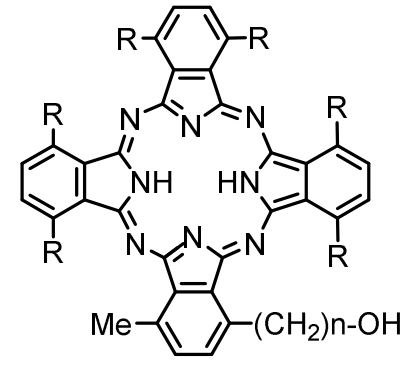

C 
Fig 2

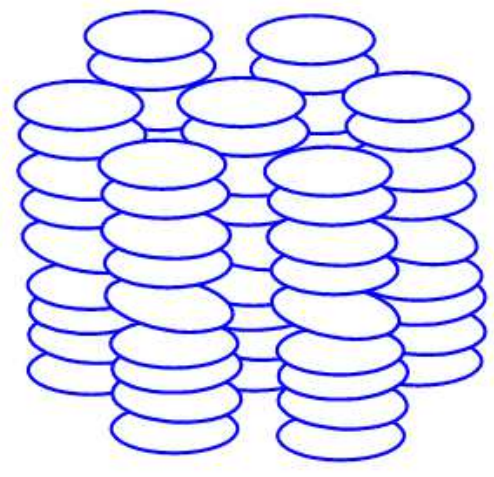

Columnar (hexagonal)

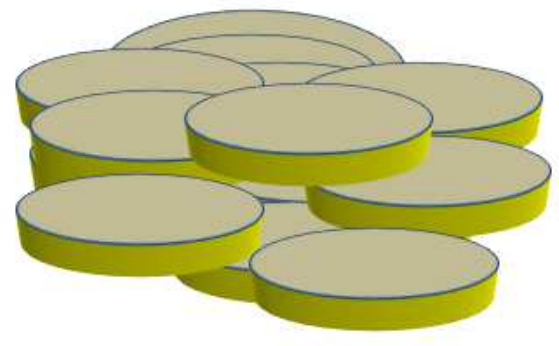

Discotic nematic 
Fig 3
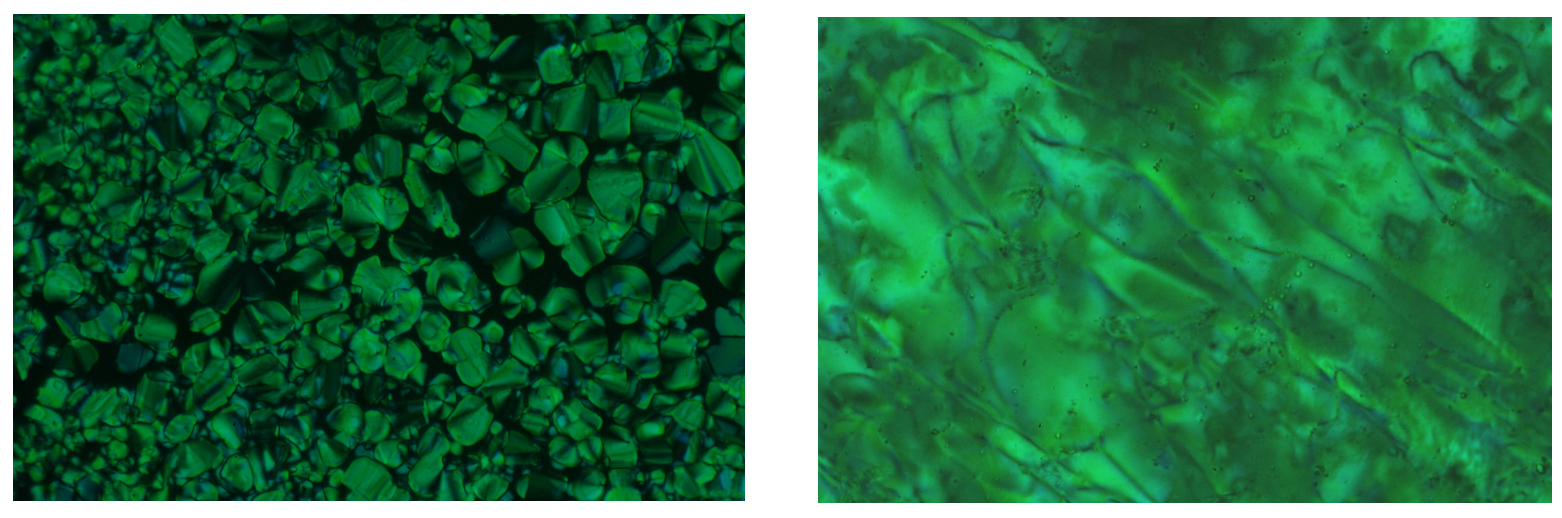


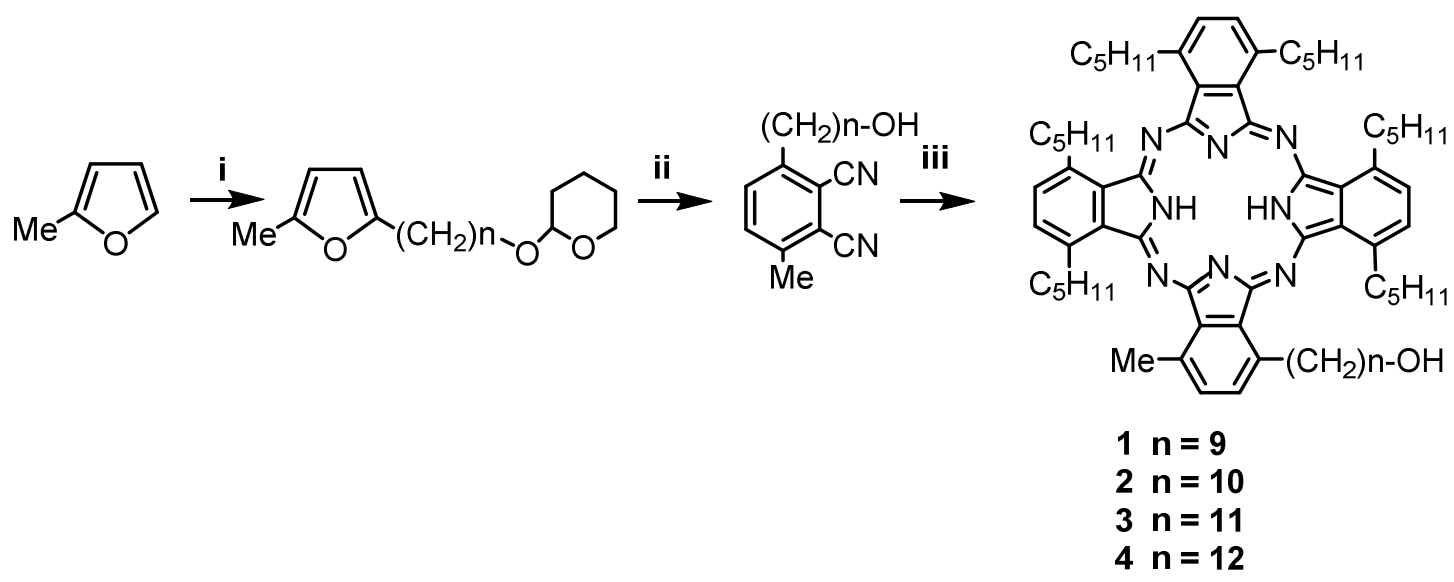


Scheme 2

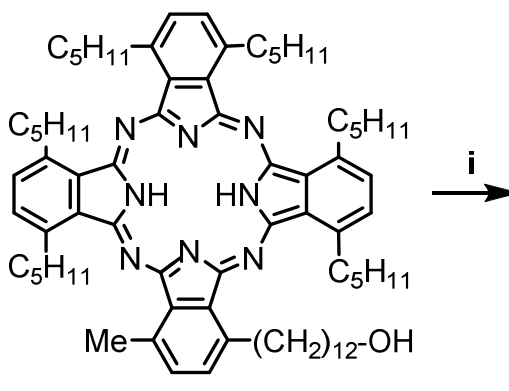

4

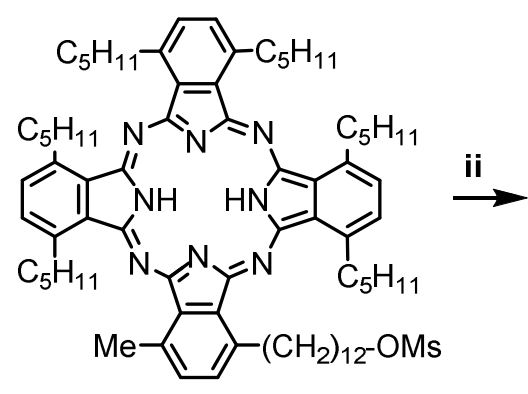

$-\left(\mathrm{CH}_{2}\right)_{12}-\mathrm{OMs}$

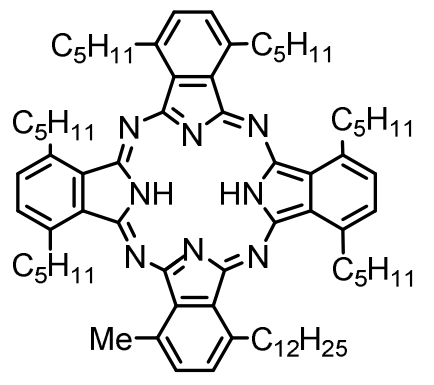

5 